\title{
Fostering antioxidant defences: up-regulation of antioxidant genes or antioxidant supplementation?
}

\author{
Jose Viña*, Mari-Carmen Gomez-Cabrera and Consuelo Borras ${ }^{1}$ \\ Department of Physiology, Faculty of Medicine, University of Valencia \\ ${ }^{1}$ Catholic University of Valencia, Valencia, Spain
}

Vitamins have traditionally been considered as food components that are required in the normal diet to prevent deficiencies. However, a newer concept of the function of vitamins in nutrition has taken them beyond simply prevention of deficiency symptoms. This concept considers that many vitamins, when taken in relatively larges doses, have important functions beyond preventing deficiencies. Linus Pauling was instrumental in putting forward this concept, particularly for vitamin $\mathrm{C}$. Thus, relatively high intakes of vitamins, and in particular vitamins $\mathrm{C}$ and $\mathrm{E}$ which are antioxidants, are considered to be healthy for the human population. This may be true in some special situations such as, for instance, the prevention of Alzheimer's disease progression. However, recent epidemiological evidence has not supported the claim that antioxidant vitamins increase well-being and prolong life span. In fact, vitamin supplementation may be even detrimental and reduce life span. A new concept that we would like to put forward is that nutrients up-regulate the endogenous antioxidant defences. This is particularly true in the case of phytoestrogens for example, which bind to oestrogen receptors and eventually up-regulate the expression of antioxidant genes. In this review we discuss the pros and cons of antioxidant vitamin supplementation and also the possibility that the ingestion of some nutrients may be very effective in increasing antioxidant defences by up-regulating the activity of antioxidant enzymes which are normally present in the cell.

Vitamins: Nutritional-supplements: Exercise: Flavonoids

The classical role of vitamins in biology and medicine was essentially centred in the prevention of deficiencies. Historically vitamins were discovered as the means to prevent diseases, which were caused by the lack of such vitamins.

The modern concept of vitamins, which we discuss in this review article, and which basically deals with the idea that taking high doses of some vitamins may be good for health is due to the influential figure Linus Pauling ${ }^{1,2}$. Before we go any further, it is important to state that no matter whether Pauling's ideas are correct or incorrect in view of modern evidence, his influence in this field has been enormous and beneficial. Of course, the progress of science deals with testing and sometimes eventually disproving old theories with new facts, which are on many occasions obtained by new methods. But this by no means detracts from the great effort of those who have advanced the scientific progress in this area, even if their ideas were partially wrong (as they always are in science). Linus Pauling, in his books "Vitamin C, the common cold and the flu" and "How to live longer and feel better", , displayed a great enthusiasm for the intake of high doses of one vitamin, namely vitamin C. His ideas may be now outdated. Much recent evidence suggests that taking large doses of a single vitamin may not confer beneficial effects on health. Some reports even go as far as saying that they may be harmful. Later in this article, we will provide recent scientific evidence showing that large doses of one or other vitamin do not improve the health and well-being of individuals.
But there is another point that is worth mentioning: in modern societies, not only in the poorer countries, but also in the so-called First World, large parts of the population are under-nourished. Some people may be grossly overweight but their intake of vitamins and minerals may be only marginally adequate, or even clearly deficient ${ }^{3}$. In fact, large parts of the populations, both in the United States and in Europe may be deficient in one or other micronutrient ${ }^{3}$. Analytical examination of great numbers of individuals may not be economically feasible. This being the case Ames has suggested that it may be advisable to propose that large parts of the population take multivitamin complexes which are harmless, and which may cover hidden sub-clinical deficiencies ${ }^{3}$. Such deficiencies may cause impairment in performance and increase the susceptibility to disease. Evidence for this will also be discussed in this review paper. Finally, we will provide data showing that boosting antioxidant defences by healthy practices such as moderate physical exercise or taking phytoestrogens may be perhaps the best way of improving antioxidant status.

\section{Pros and cons of supplementation with high doses of vitamins}

Many common human diseases, including atherosclerosis, cardiovascular disease, hypertension, cataracts, Alzheimer's, diabetes, cancer as well as physiological processes such as aging, have free radical reactions as an underlying mechanism of injury $^{45}$. This is the reason why, for years, many benefits 
have been postulated for antioxidant administration both in health and in disease ${ }^{6,7}$.

Reactive oxygen and nitrogen species (RONS) are well recognised for playing a dual role, both unfavourable and beneficial, to the cells ${ }^{8}$. Overproduction of RONS results in oxidative stress, a deleterious process that can be an important mediator of damage to cell structures: lipid, proteins and $\mathrm{DNA}^{9}$. In contrast, there is evidence that moderate changes in RONS concentrations in cells act as signals and may be beneficial to the cells ${ }^{4}$. Although supplementation with antioxidant vitamins has shown positive anti-atherogenic, anti-carcinogenic and immunomodulatory effects ${ }^{10-12}$, the health benefits of different antioxidants have been the subject of debate and controversy lately ${ }^{13}$.We consider that the contradictory data can be explained by taking into account several aspects: the type of antioxidant vitamins used as dietary supplements, the doses, the antioxidant and the health status in the supplemented individuals and the duration of the intervention programmes.

\section{The antioxidant vitamins: dose is important for health effects}

There are several enzyme systems within the body that effectively scavenge free radicals (see below). In addition, the cell has many low molecular weight antioxidants. Prominent amongst these are the main antioxidant vitamins, $\mathrm{C}$ and E. In large doses some vitamins show undesirable side effects and these tend to increase in severity with increasing dosage. The likelihood of consuming too much of any vitamin from food is remote, but overdosing from vitamin supplementation does occur. At high enough doses some vitamins cause side effects, such as nausea, diarrhoea, or vomiting ${ }^{12}$. When vitamin side effects emerge, recovery is often achieved by reducing the dosage. Furthermore, the concentrations of vitamins that an individual can tolerate vary widely, and appear to be related to age and state of health.

\section{Vitamin C}

Several studies have pointed to an association between vitamin $\mathrm{C}$ intake and chronic diseases. For instance, it was reported that vitamin $\mathrm{C}$ supplementation lowered arterial blood pressure ${ }^{14}$. On the other hand, the role of vitamin $\mathrm{C}$ in cancer prevention remains controversial in spite of a number of studies that have been conducted over the last 30 years to clarify this point. Nobel laureate Pauling and his colleague Cameron recommended the use of high doses of ascorbic acid to cure and prevent the common cold infections as well as to prevent the onset of cancer ${ }^{15,16}$. In a 4-y prospective study with 30,466 men and women, the risk of mortality due to all causes for those in the highest quintile of plasma ascorbate concentration was about one-half that of those in the lowest quintile of plasma ascorbate concentration ${ }^{17}$. Similar results were also reported for men but not for women ${ }^{18}$. Another study indicated that free-living elderly who consumed citrus fruits twice a week had adjusted risks of dying that were half those of elderly who consumed citrus fruit less than once a week ${ }^{19}$. Considerable biochemical and physiological evidence suggests that ascorbic acid functions as a free radical scavenger and inhibits the formation of potentially carcinogenic N-nitroso compounds from nitrates, including nitrites stomach and thus offers protection against stomach cancer $^{20,21}$. However, there are also studies that do not show any positive effect after supplementation with vitamin $C^{22,23}$. Clinical studies on cancer patients carried out at the Mayo Clinic showed no significant differences between vitamin $C$ and placebo groups with particular regard to survival time ${ }^{24}$. Moreover Lee et al. reported that lipid hydroperoxides can react with ascorbic acid to form products that could potentially damage DNA, suggesting that genotoxic metabolites from lipid hydroperoxides might be formed ${ }^{25}$. In this scenario, ascorbic acid could enhance mutagenesis and risk of cancer. However the physiological relevance of these results is yet to be established in in vivo experiments ${ }^{12}$. Finally, it has been reported that tumour cells contain large amounts of ascorbic acid ${ }^{26}$. It has been speculated that high levels of ascorbic acid in cancer cells may interfere with chemotherapy or radiation therapy since these therapies induce cell death by oxidative mechanisms. Thus, ascorbic acid supplementation might make cancer treatment less effective. More studies are needed to understand the role of ascorbic acid in tumour cells and the speculative contraindication of ascorbic acid for cancer chemotherapy.

Another important aspect that should be taken into account when supplementing with vitamin $\mathrm{C}$ is the possibility that it acts as a pro-oxidant in vivo. These pro-oxidative reactions of vitamin $\mathrm{C}$ readily occur in vitro and recently it has been demonstrated that they can also have relevance in in vivo experiments ${ }^{27}$. A high intake of iron along with ascorbic acid could increase in vivo lipid peroxidation of LDL and therefore could increase the risk of atherosclerosis ${ }^{28}$. However, another study demonstrated that in iron overloaded plasma, ascorbic acid acts as an antioxidant and prevents oxidative damage to lipids in vivo ${ }^{29}$.

Clearly, the possible toxicity of large doses of vitamin C requires more experimental and clinical studies.

\section{Vitamin E}

Numerous epidemiological studies have shown that a high intake of vitamin $\mathrm{E}$ is related to a lower risk of age-related and chronic diseases. Experimental studies have suggested substantial health benefits from vitamin $\mathrm{E}$ in disease prevention and therapy. $\alpha$-tocopherol, the major form of vitamin $\mathrm{E}$ in the human body, appears to have important health benefits; these include protection against reproductive diseases (preeclampsia) $^{30}$, age-related eye diseases (cataract, macular degeneration) ${ }^{31,32}$, metabolic disorders (diabetes mellitus) ${ }^{33}$ and neurodegenerative disorders (Alzheimer's) ${ }^{7}$.

However recent data show unfavourable, rather than beneficial, effects after supplementation with this antioxidant vitamin. In 2003, a meta-analysis was performed to assess the effect of $\alpha$-tocopherol and $\beta$-carotene, or both, on long-term cardiovascular mortality and morbidity ${ }^{34}$. No positive effect of high doses of vitamins in different populations was shown. Due to the lack of data for the efficacy of vitamin E, the main conclusion derived from this study was that its supplementation should be discontinued because of its risks. The authors did not support the routine use of $\beta$-carotene, as previously shown especially in smokers ${ }^{35}$. In other studies 200 IU per day of vitamin E did not have a significant effect 
on lowering the incidence of respiratory tract infections in elderly nursing home residents ${ }^{36}$ and 600 IU of the same vitamin, taken every other day, provided no overall benefit for major cardiovascular events or cancer in healthy women ${ }^{37}$. Finally, a recent study associated $\beta$-carotene, vitamin A, and vitamin $\mathrm{E}$ supplementation with increased mortality ${ }^{13}$.

Thus, the overall conclusion that can be drawn from these studies is that the general population should not be advised to take supplements with vitamin E. This, however, does not mean that vitamin E supplements should not be indicated in cases of vitamin $\mathrm{E}$ deficiency, or prevention of deficiency. As mentioned previously, Sano et al. published a seminal paper in which the efficacy of vitamin $E$ in delaying the physical deterioration associated with advanced forms of Alzheimer's disease was shown ${ }^{7}$. Our research group reported that high doses of vitamin $\mathrm{C}$ and $\mathrm{E}$ prevented muscle damage associated with the intake of anti-retroviral drugs which are commonly used to treat $\operatorname{AIDS}^{11}$. There is also a report that supplementation with vitamin $\mathrm{E}$, but not other antioxidants, was effective in reducing pulmonary viral titres and preventing an influenzamediated decrease in food intake and weight loss in mice ${ }^{10}$. The fact that other antioxidants were not effective led to the conclusion that, in addition to its effect as an antioxidant, vitamin $\mathrm{E}$ might be acting via other mechanisms which might not be related to its antioxidant properties.

\section{The concept of micronutrient malnutrition and deficiency}

Micronutrient malnutrition is a term commonly used to refer to vitamin and mineral nutritional deficiency diseases. Diets which lack adequate amounts of essential vitamins and minerals lead to such diseases. Vitamin A deficiency, iron deficiency anaemia and iodine deficiency disorders are among the most common forms of micronutrient malnutrition. Other micronutrients found in food, including vitamins such as thiamine, niacin, riboflavin, folate, vitamins $\mathrm{C}$ and $\mathrm{D}$, and minerals such as calcium, selenium and zinc can also significantly affect health when dietary deficiencies exist. As stated, these deficiencies cause diseases. Well-known human vitamin deficiencies involve thiamine (beriberi), niacin (pellagra), vitamin C (scurvy) and vitamin D (rickets). In much of the developed world, such deficiencies are rare; this is due to (1) an adequate supply of food; and (2) the addition of vitamins and minerals, often called fortification, to common foods ${ }^{38,39}$.

Micronutrient deficiency is a term used to refer to the situation where the levels of micronutrients are lower than requirements, but are high enough to prevent the development of diseases mentioned.

Ames stated, "our daily intake of the 40 essential micronutrients is commonly thought to be adequate" but "the optimum amount of vitamins, minerals, and essential biochemicals is the amount that maximizes a healthy life span, and is likely to be higher than the amount needed to prevent acute deficiency disease" ${ }^{, 40}$.

\section{Micronutrient deficiency diseases}

Micronutrients participate in the body in almost all metabolic and developmental processes ${ }^{41}$. Inadequate intakes may result in chronic metabolic disruption. Several micronutrient deficiencies are associated with mitochondrial decay, oxidant leakage and cellular aging ${ }^{42}$, which can be responsible for degenerative disease such as vascular dementia ${ }^{43}$, DNA damage (chromosome breaks) in cultured human cells or in vivo ${ }^{44}$, or late onset diseases such as cancer.

It is crucial for the understanding of micronutrient deficiency diseases to distinguish them from micronutrient malnutrition. The former occurs when the micronutrient intake is lower than the levels we need for metabolic processes, but are high enough to prevent the development of the diseases that result from the latter (e.g. rickets, scurvy, etc.).

Diseases related to micronutrient deficiency, such as degenerative diseases or cancer, are caused mainly by the chronic metabolic disruption which is translated into a mitochondrial decay.

Simple preventive measures like increasing the uptake of relatively low doses of multivitamin and multimineral supplements may be instrumental in lowering the incidence of age-associated degenerative diseases. These ideas are summarised in the Fig. 1.

\section{Increasing endogenous antioxidant defences versus increasing the uptake of antioxidant vitamins}

The cell possesses a number of extremely powerful mechanisms to counteract the harmful effects of the inevitable free radicals which are formed as a consequence of aerobic metabolism. Of critical importance among these are the enzymatic systems which catalytically detoxify free radicals and other reactive oxygen species. For instance, the superoxide dismutase - glutathione peroxidase system serves to detoxify superoxide which is formed in the mitochondrial respiratory chain and to convert it to water via the intermediary formation of hydrogen peroxide. Other critically important enzymes exist, for instance catalase which is present in peroxisomes and which detoxifies hydrogen peroxide very effectively, converting it to water. Moreover, the importance of other enzyme systems, such as thioredoxin, glutaredoxin or sestrins amongst other has been emphasised. From a

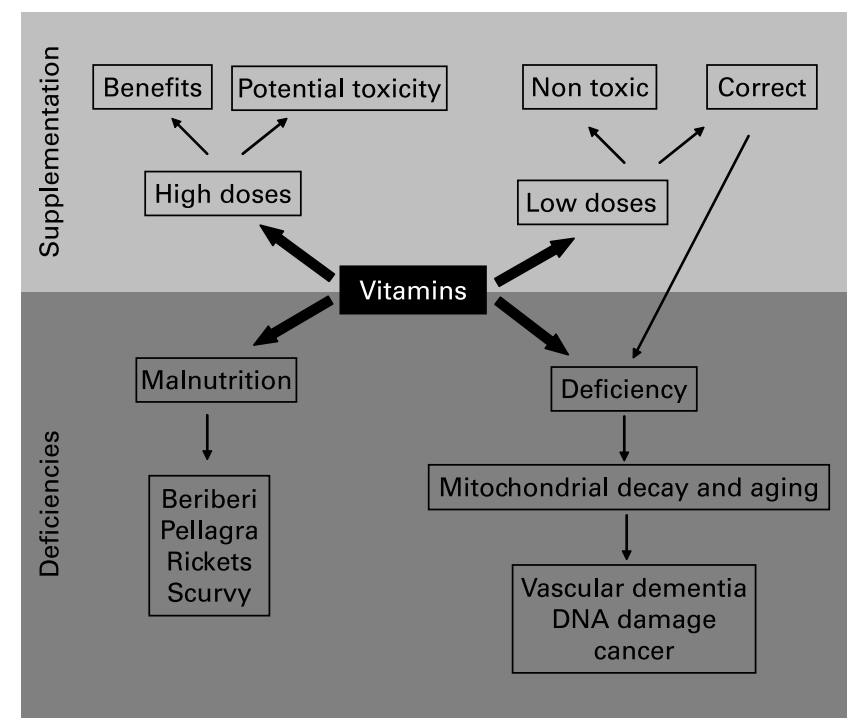

Fig. 1. Summary of the effects of vitamin deficiencies and supplementation. 
nutritional and physiological standpoint, it may be advisable to increase the expression and activity of these antioxidant enzyme systems as a way to improve the overall antioxidant defence capacity of the cells. Thus, we, as well as other laboratories, have searched for mechanisms which could increase the activity of critical antioxidant enzymes. In recent times, we have been considering the observation that females in many species including humans, live longer than males $^{45}$. We concluded that this is due to the beneficial effect of oestradiol which is effective at up-regulating the expression of the genes coding for antioxidant enzymes such as glutathione peroxidase and superoxide dismutase ${ }^{45}$. Obviously, oestrogens cannot be used as nutritional supplements because they have many disadvantages, particularly in males where they are powerfully feminising. Phytoestrogens, on the other hand, lend themselves as possible candidates for supplementation to increase the endogenous antioxidant defences of cells, animals, and eventually human beings. Phytoestrogens are not feminising (because they bind quite specifically to oestrogen $\beta$ receptors and the feminising effects are usually associated with the oestrogen receptor $\alpha$ activation $)^{46}$. Moreover, no reports of the carcinogenic effect of phytoestrogens have been published. They also have a number of beneficial effects like increasing bone density, lowering hot flushes associated with menopause and even partially preventing the incidence of breast cancers ${ }^{47}$. We have found that genistein has beneficial effects in that it increases the expression and activity of longevity-associated genes particularly superoxide dismutase and glutathione peroxidase in a human cell line $\mathrm{e}^{48}$. Moreover, in in vivo experiments, in which blood pressure was measured in rats using telemetric methods, administration of phytoestrogens in the form of a soya-enriched diet lowered blood pressure ${ }^{49} \mathrm{We}$ found that this was due to the up-regulation of the expression of genes such as the endothelial nitric oxide synthase. Therefore, evidence is gathering that increasing the expression of antioxidant and other longevity-related genes by the ingestion (in the form of dietary modifications or of supplementation) of phytoestrogens or by increased physical activity in the form of leisurely sport activities that do not cause exhaustion, increases the expression and activity of longevity-related genes and may be the ideal ways of improving endogenous antioxidant defences rather than trying to increase them by supplementation with antioxidant vitamins.

\section{Conflict of interest statement}

The authors work was supported by grants SAF 2004-03 755 and BFU2007-65 803/BFI to J. V., GV06/289 to M. C. G-C and by grant (ISCIII2006-RED13-027) from the "Red Temática de investigación cooperativa en envejecimiento y fragilidad (RETICEF). Instituto de Salud Carlos III" The authors have no conflict of interests to declare.

\section{References}

1. Pauling L (1973) Vitamin C, the common cold and the flu. San Francisco: WJ Freeman \& Co.

2. Pauling L (1986) How to live longer and feel better. San Francisco: Freeman \& Co.
3. Ames BN, Atamna H \& Killilea DW (2005) Mineral and vitamin deficiencies can accelerate the mitochondrial decay of aging. Mol Aspects Med. 26, 363-378.

4. Valko M, Leibfritz D, Moncol J, Cronin MT, Mazur M \& Telser J (2007) Free radicals and antioxidants in normal physiological functions and human disease. Int J Biochem Cell Biol 39, 44-84.

5. Pallardo FV, Asensi M, Garcia de la Asuncion J, Anton V, Lloret A, Sastre J \& Vina J (1998) Late onset administration of oral antioxidants prevents age-related loss of motor co-ordination and brain mitochondrial DNA damage. Free Radic Res 29, 617-623.

6. Taylor A, Jacques PF, Chylack LT, Hankinson SE, Khu PM, Rogers G, Friend J, Tung W, Wolfe JK, Padhye N \& Willett WC (2002) Long-term intake of vitamins and carotenoids and odds of early age-related cortical and posterior subcapsular lens opacities. Am J Clin Nutr 75, 540-549.

7. Sano M, Ernesto C, Thomas RG, Klauber MR, Schafer K, Grundman M, Woodbury P, Growdon J, Cotman CW, Pfeiffer E, Schneider LS \& Thal LJ (1997) A controlled trial of selegiline, alpha-tocopherol, or both as treatment for Alzheimer's disease. The Alzheimer's Disease Cooperative Study. $N$ Engl J Med 336, 1216-1222.

8. Gomez-Cabrera MC, Borras C, Pallardo FV, Sastre J, Ji LL \& Vina J (2005) Decreasing xanthine oxidase-mediated oxidative stress prevents useful cellular adaptations to exercise in rats. J Physiol 567, 113-120.

9. Halliwell B (1994) Free radicals and antioxidants: a personal view. Nutr Rev 52, 253-265.

10. Han SN, Meydani M, Wu D, Bender BS, Smith DE, Vina J, Cao G, Prior RL \& Meydani SN (2000) Effect of long-term dietary antioxidant supplementation on influenza virus infection. J Gerontol A Biol Sci Med Sci 55, B496-B503.

11. de la Asuncion JG, del Olmo ML, Sastre J, Millan A, Pellin A, Pallardo FV \& Vina J (1998) AZT treatment induces molecular and ultrastructural oxidative damage to muscle mitochondria. Prevention by antioxidant vitamins. J Clin Invest 102, 4-9.

12. Naidu KA (2003) Vitamin $C$ in human health and disease is still a mystery? An overview. Nutr J 2, 7-11.

13. Bjelakovic G, Nikolova D, Gluud LL, Simonetti RG \& Gluud C (2007) Mortality in randomized trials of antioxidant supplements for primary and secondary prevention: systematic review and meta-analysis. JAMA 297, 842-857.

14. Block G, Mangels AR, Norkus EP, Patterson BH, Levander OA \& Taylor PR (2001) Ascorbic acid status and subsequent diastolic and systolic blood pressure. Hypertension 37, 261-267.

15. Cameron E \& Pauling L (1974) The orthomolecular treatment of cancer. I. The role of ascorbic acid in host resistance. Chem Biol Interact 9, 273-283.

16. Cameron E, Pauling L \& Leibovitz B (1979) Ascorbic acid and cancer: a review. Cancer Res 39, 663-681.

17. Khaw KT, Bingham S, Welch A, Luben R, Wareham N, Oakes S \& Day N (2001) Relation between plasma ascorbic acid and mortality in men and women in EPIC-Norfolk prospective study: a prospective population study. European Prospective Investigation into Cancer and Nutrition. Lancet 357, 657-663.

18. Loria CM, Klag MJ, Caulfield LE \& Whelton PK (2000) Vitamin C status and mortality in US adults. Am J Clin Nutr 72, 139-145.

19. Fortes C, Forastiere F, Farchi S, Rapiti E, Pastori G \& Perucci CA (2000) Diet and overall survival in a cohort of very elderly people. Epidemiology 11, 440-445.

20. Drake IM, Davies MJ, Mapstone NP, Dixon MF, Schorah CJ, White KL, Chalmers DM \& Axon AT (1996) Ascorbic acid may protect against human gastric cancer by scavenging mucosal oxygen radicals. Carcinogenesis 17, 559-562. 
21. Block G (1991) Epidemiologic evidence regarding vitamin C and cancer. Am J Clin Nutr 54, 1310S-1314S.

22. Jacobs EJ, Connell CJ, Patel AV, Chao A, Rodriguez C, Seymour J, McCullough ML, Calle EE \& Thun MJ (2001) Vitamin $\mathrm{C}$ and vitamin $\mathrm{E}$ supplement use and colorectal cancer mortality in a large American Cancer Society cohort. Cancer Epidemiol Biomarkers Prev 10, 17-23.

23. Creagan ET, Moertel CG, O'Fallon JR, Schutt AJ, O'Connell MJ, Rubin J \& Frytak S (1979) Failure of high-dose vitamin $\mathrm{C}$ (ascorbic acid) therapy to benefit patients with advanced cancer. A controlled trial. $N$ Engl J Med 301, 687-690.

24. Moertel CG, Fleming TR, Creagan ET, Rubin J, O'Connell MJ \& Ames MM (1985) High-dose vitamin C versus placebo in the treatment of patients with advanced cancer who have had no prior chemotherapy. A randomized double-blind comparison. $N$ Engl J Med 312, 137-141.

25. Lee SH, Oe T \& Blair IA (2001) Vitamin C-induced decomposition of lipid hydroperoxides to endogenous genotoxins. Science 292, 2083-2086.

26. Agus DB, Vera JC \& Golde DW (1999) Stromal cell oxidation: a mechanism by which tumors obtain vitamin C. Cancer Res $\mathbf{5 9}$, 4555-4558.

27. Childs A, Jacobs C, Kaminski T, Halliwell B \& Leeuwenburgh C (2001) Supplementation with vitamin C and N-acetyl-cysteine increases oxidative stress in humans after an acute muscle injury induced by eccentric exercise. Free Radic Biol Med 31, $745-753$.

28. Berger TM, Polidori MC, Dabbagh A, Evans PJ, Halliwell B, Morrow JD, Roberts LJ \& Frei B (1997) Antioxidant activity of vitamin $\mathrm{C}$ in iron-overloaded human plasma. $\mathrm{J}$ Biol Chem 272, 15656-15660.

29. Chen K, Suh J, Carr AC, Morrow JD, Zeind J \& Frei B (2000) Vitamin $\mathrm{C}$ suppresses oxidative lipid damage in vivo, even in the presence of iron overload. Am J Physiol Endocrinol Metab 279, E1406-E1412.

30. Chappell LC, Seed PT, Briley AL, Kelly FJ, Lee R, Hunt BJ, Parmar K, Bewley SJ, Shennan AH, Steer PJ \& Poston L (1999) Effect of antioxidants on the occurrence of pre-eclampsia in women at increased risk: a randomised trial. Lancet 354, $810-816$.

31. Mares-Perlman JA, Lyle BJ, Klein R, Fisher AI, Brady WE, VandenLangenberg GM, Trabulsi JN \& Palta M (2000) Vitamin supplement use and incident cataracts in a population-based study. Arch Ophthalmol 118, 1556-1563.

32. Belda JI, Roma J, Vilela C, Puertas FJ, Diaz-Llopis M, BoschMorell F \& Romero FJ (1999) Serum vitamin E levels negatively correlate with severity of age-related macular degeneration. Mech Ageing Dev 107, 159-164.

33. Jain SK, McVie R \& Smith T (2000) Vitamin E supplementation restores glutathione and malondialdehyde to normal concentrations in erythrocytes of type 1 diabetic children. Diabetes Care 23, 1389-1394.

34. Vivekananthan DP, Penn MS, Sapp SK, Hsu A \& Topol EJ (2003) Use of antioxidant vitamins for the prevention of cardiovascular disease: meta-analysis of randomised trials. Lancet 361, 2017-2023.
35. Virtamo J, Pietinen P, Huttunen JK, Korhonen P, Malila N, Virtanen MJ, Albanes D, Taylor PR \& Albert P (2003) Incidence of cancer and mortality following alpha-tocopherol and beta-carotene supplementation: a postintervention follow-up. JAMA 290, 476-485.

36. Meydani SN, Leka LS, Fine BC, Dallal GE, Keusch GT, Singh MF \& Hamer DH (2004) Vitamin E and respiratory tract infections in elderly nursing home residents: a randomized controlled trial. JAMA 292, 828-836.

37. Lee IM, Cook NR, Gaziano JM, Gordon D, Ridker PM, Manson JE, Hennekens CH \& Buring JE (2005) Vitamin E in the primary prevention of cardiovascular disease and cancer: The Women's Health Study: a randomized controlled trial. JAMA 294, 56-65.

38. West CE \& Hautvast JG (1997) Nutrition. From 'whither' to 'wither' micronutrient malnutrition? Lancet 350, Suppl. 3, SIII15.

39. Dietary Reference Intakes (2001) Vitamins The National Academies The Merck Manual: Nutritional Disorders: Vitamin Introduction.

40. Ames BN (2005) Increasing longevity by tuning up metabolism. To maximize human health and lifespan, scientists must abandon outdated models of micronutrients. EMBO 6, S20-S24.

41. McCann JC \& Ames BN (2007) An overview of evidence for a causal relation between iron deficiency during development and deficits in cognitive or behavioral function. Am J Clin Nutr 85, 931-945.

42. Ames BN (2006) Low micronutrient intake may accelerate the degenerative diseases of aging through allocation of scarce micronutrients by triage. Proc Natl Acad Sci USA 103, $17589-17594$.

43. Meydani M (2001) Nutrition interventions in aging and ageassociated disease. Ann N Y Acad Sci 928, 226-235.

44. Fenech M \& Ferguson LR (2001) Vitamins/minerals and genomic stability in humans. Mutat Res 475, 1-6.

45. Borras C, Sastre J, Garcia-Sala D, Lloret A, Pallardo FV \& Vina J (2003) Mitochondria from females exhibit higher antioxidant gene expression and lower oxidative damage than males. Free Radic Biol Med 34, 546-552.

46. Barkhem T, Carlsson B, Nilsson Y, Enmark E, Gustafsson J \& Nilsson S (1998) Differential response of estrogen receptor alpha and estrogen receptor beta to partial estrogen agonists/ antagonists. Mol Pharmacol. 54, 105-112.

47. Cassidy A (2003) Potential risks and benefits of phytoestrogenrich diets. Int J Vitam Nutr Res. 73, 120-126.

48. Borras C, Gambini J, Gomez-Cabrera MC, Sastre J, Pallardo FV, Mann GE \& Vina J (2006) Genistein, a soy isoflavone, up-regulates expression of antioxidant genes:involvement of estrogen receptors, ERK1/2, and NFkappaB. FASEB J. 20, $2136-2138$.

49. Mahn K, Borras C, Knock GA, Taylor P, Khan IY, Sugden D, Poston L, Ward JP, Sharpe RM, Vina J, Aaronson PI \& Mann GE (2005) Dietary soy isoflavone induced increases in antioxidant and eNOS gene expression lead to improved endothelial function and reduced blood pressure in vivo. FASEB J. 19, $1755-1757$. 